\title{
Development of functionalized carrageenan, chitosan and alginate as polymeric chelating ligands for water softening
}

\author{
K. A. Ali $^{1,2}$ - M. E. Hassan ${ }^{1,3}$ - M. M. M. Elnashar ${ }^{1,4}$
}

Received: 1 April 2016/Revised: 17 January 2017/ Accepted: 21 February 2017

(C) Islamic Azad University (IAU) 2017

\begin{abstract}
Chitosan, carrageenan and alginate are among the most abundant biopolymers in nature. They were prepared in uniform beads shape with a diameter of $2 \mathrm{~mm} \pm 10 \%$, using the encapsulator for removal of calcium, magnesium and iron cations from hard water. Solutions of $100-500 \mathrm{mg} / \mathrm{L}$ were prepared from each cation, and the detection of cations was carried out using atomic absorption spectrometer. Carrageenan and chitosan were able to chelate the three cations without further modification. However, alginate beads succeeded to chelate iron and magnesium and failed to chelate any calcium ions; in contrast, it increased the initial calcium concentration! That could be due to the pre-cross-linking of alginate beads using calcium chloride solution, which may be leaked back to the solution. However, grafting the alginate beads with polyethyleneimine and bromoacetic acid rectified this problem and the new functional group, $-\mathrm{COOH}$, has been proved using the FT-IR. Optimization of the results in terms of beads weight $(0.25-3.0 \mathrm{~g})$ and cations concentrations
\end{abstract}

Editorial responsibility: BV Thomas.

Electronic supplementary material The online version of this article (doi:10.1007/s13762-017-1298-y) contains supplementary material, which is available to authorized users.

\section{K. A. Ali}

kornykhlil@gmail.com

1 Center of Excellence, Advanced Materials and Nanobiotechnology Group, National Research Centre, Dokki, Giza 12622, Egypt

2 Applied Organic Chemistry Department, National Research Centre, Dokki, Giza 12622, Egypt

3 Chemistry of Natural and Microbial Products Department, National Research Centre, Dokki, Giza 12622, Egypt

4 Biomedical Sciences Department, Health Sciences School, Curtin University, Perth 6102, Australia
(100-500 mg/L) has shown that most biopolymeric beads can chelate $85-100 \%$ of the cations in concentrations up to $500 \mathrm{mg} / \mathrm{L}$. According to our finding, we came up with the recommendation to use chitosan for chelation of calcium and iron as it showed $100 \%$ chelation efficiency of both cations, whereas carrageenan is highly recommended for chelation of iron and magnesium, as it showed 100 and $98 \%$ chelation efficiency, respectively. Further work can be done on the reusability of the beads and scale up for the industrial use.

Keywords Biopolymers - Metal ions - Chelation · Water purification · Grafting

\section{Introduction}

Softening of ground water is an important process to provide fresh drinking water in many places around the world. Likewise, seawater is composed of $96.7 \%$ water and $3.3 \%$ dissolved salts. The main seven elements ( $\mathrm{Na}, \mathrm{K}, \mathrm{Mg}, \mathrm{Ca}, \mathrm{Br}, \mathrm{S}$ and $\mathrm{Cl}$ ) account for $93.5 \%$ of the dissolved salts (Ohya et al. 2001). The presence of certain metal ions like magnesium, and calcium principally as chlorides, sulfates and bicarbonates causes a variety of problems. For example, hard water leads to the buildup of lime scale, which promotes galvanic corrosion and can foul plumbing. Magnesium and calcium are present in reasonably high concentrations of $1.29-1.77$ and $0.23-0.50 \mathrm{~g} /$ L, respectively (El-Sayed et al. 2014). In addition to magnesium and calcium, iron can cause a lot of troubles even in small quantities, as little as $0.3 \mathrm{ppm}$. Iron affects the tastes of beverages and foods, can cause staining of flooring, sinks, fixtures, sinks and can contribute to the blockage of pipes. Thus, iron removal is considered an imperative phase of water treatment (Chaturvedi and Dave 2012). Many resins have been developed to remove undesired cations from water such 
as Purolite SST60 via its sulfonic group and Lewatit MonoPlus TP207XL via its iminodiacetic acid (El-Sayed et al. 2014). Lewatit cation exchanger was used and adsorbed up to $110 \mathrm{mg} / \mathrm{L} \mathrm{Mg}^{2+}$ and $20 \mathrm{mg} / \mathrm{L} \mathrm{Ca}^{2+}$ (Muraviev et al. 1996).

Biopolymeric materials are naturally occurring polymers used in different applications and recently received a great attention (Elnashar 2011). They are used for valuable and important applications because they have many features and properties such as being renewable, non-toxic, biocompatible and biodegradable. Furthermore, they are considered as lowcost materials in comparison with some of the synthetic materials (Ali et al. 2013; Elnashar 2010, Elnashar and Hassan 2014 and Elnashar 2011; Deans and Dixon 1992; Nazarudin et al. 2011; Seki and Suzuki 1995; Jang et al. 1991). Carrageenan, chitosan and alginate are natural and biodegradable biopolymers that are suitable for developing novel types of materials containing different functional groups (sulfate, amino and carboxylic acid, respectively) for different applications (Nah and Hwang 2007; Zhao et al. 2011).

The aim of this study is to use biopolymers such as alginate, chitosan and carrageenan to chelate the calcium, magnesium and iron from hard water. In addition, these biopolymers are biocompatible, biodegradable and safer to human. The three biopolymers were produced in uniform beads shape using the encapsulator. The experiments were optimized to remove the maximum concentration of cations from hard water. Concentrations of $\mathrm{Ca}^{2+}, \mathrm{Mg}^{2+}$ and $\mathrm{Fe}^{2+} / \mathrm{Fe}^{3+}$ before and after purification of hard water were measured using atomic absorption spectroscopy.

\section{Materials and methods}

\section{Materials}

Sodium alginate, carrageenan polyethyleneimine (PEI) and chitosan were purchased from Sigma-Aldrich (Germany). Sodium tripolyphosphate, calcium chloride $\left(\mathrm{CaCl}_{2}\right)$ and potassium chloride $(\mathrm{KCl})$ were purchased from Park Scientific limited (UK).

\section{Methods}

\section{Preparation of alginate gel beads}

Alginate gel was prepared using the reported protocol by Elnashar et al. (2009) by dissolving $2.5 \%$ (w/v) sodium alginate (Alg) in distilled water and $0.002 \%(\mathrm{w} / \mathrm{v}) \mathrm{NaN}_{3}$ as antibacterial agent. The mixture was stirred using mechanical stirrer until complete dissolution then dropped by the Inotech Encapsulator (Fig. 1a) using a nozzle of $200 \mu \mathrm{m}$ in of $2 \%(\mathrm{w} / \mathrm{v}) \mathrm{CaCl}_{2}$ solution as a hardener to give

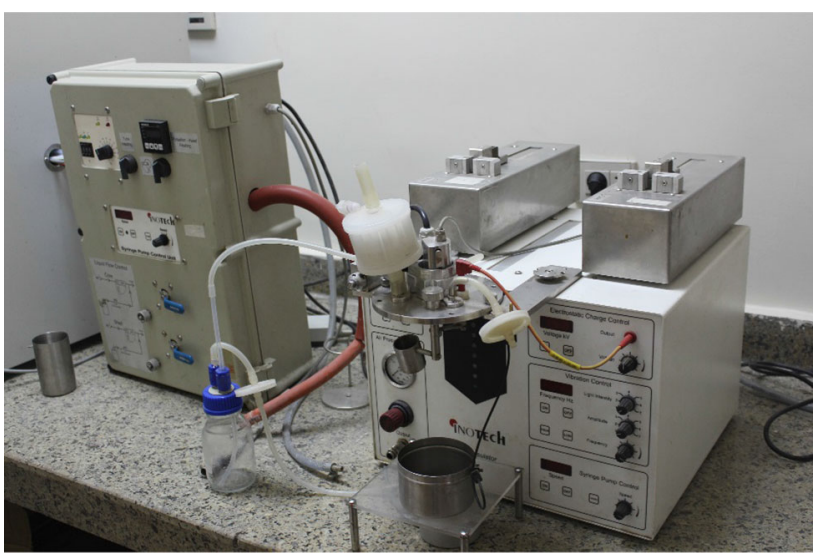

(a)

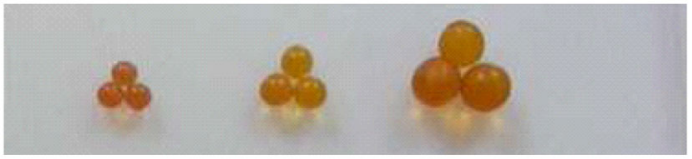

(b)

Fig. 1 a Encapsulator for making uniform gel beads. b Gel beads prepared using the encapsulator

uniform gel beads (diameter $2 \mathrm{~mm}$ ). Micrometer and optical microscope were used to check the prepared beads size.

\section{Modification of alginate gel beads}

Ten grams of alginate beads was washed thoroughly with distilled water and mixed in $(22 \mathrm{~mL} 0.2 \mathrm{M})$ sodium bicarbonate and $4 \%(\mathrm{v} / \mathrm{v})$ PEI at $\mathrm{pH} 8$, and the gel beads were stirred for $24 \mathrm{~h}$ at $50{ }^{\circ} \mathrm{C}$. Five grams of the freshly modified beads with PEI was washed with distilled water and dried under vacuum. The beads were transferred to a beaker containing $1.6 \mathrm{gm}$ bromoacetic acid in $50 \mathrm{~mL}$ water adjusted to $\mathrm{pH}$ using $2 \mathrm{M} \mathrm{NaOH}$ solution. The gel beads were stirred over night at room temperature.

\section{Preparation of chitosan gel beads}

Chitosan gel was prepared by stirring a solution of $1.5 \%$ $(\mathrm{w} / \mathrm{v})$ chitosan in $1 \%$ acetic acid using mechanical stirrer for $10 \mathrm{~h}$. The formed gel was mixed in a solution of $10 \%$ sodium tripolyphosphate for $3 \mathrm{~h}$ using encapsulator (Fig. 1a) to make gel beads.

\section{Preparation of carrageenan gel beads}

$\kappa$-Carrageenan gel was prepared using the reported protocol by Elnashar et al. (2009) [16] by dissolving 2.5\% (w/v) carrageenan in distilled water at $70{ }^{\circ} \mathrm{C}$ and $0.002 \%(\mathrm{w} / \mathrm{v})$ $\mathrm{NaN}_{3}$ as antibacterial agent. The mixture was stirred using mechanical stirrer until complete dissolution. Carrageenan gel was transferred to the encapsulator (Fig. 1a) for 
preparation of the gel beads as shown in Fig. 1b. The gel beads were cross-linked in $0.3 \mathrm{M} \mathrm{KCl}$ for $3 \mathrm{~h}$.

\section{Modification of carrageenan gel beads}

Ten grams of carrageenan gel beads was washed thoroughly with distilled water and mixed in (22 $\mathrm{mL} 0.2 \mathrm{M})$ sodium bicarbonate and $4 \%(\mathrm{v} / \mathrm{v}) \mathrm{PEI}$ at $\mathrm{pH} 8$, and the gel beads were stirred for $24 \mathrm{~h}$ at $50^{\circ} \mathrm{C}$. Five grams of the freshly modified beads with PEI was washed with distilled water and dried under suction. The beads were transferred to a beaker containing $1.6 \mathrm{gm}$ bromoacetic acid in $50 \mathrm{~mL}$

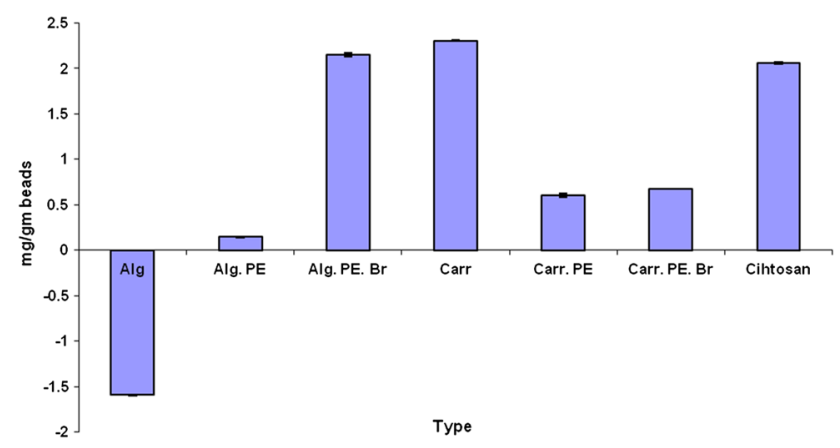

Fig. 2 Activity of the prepared beads as chelating agents for $\mathrm{Ca}^{2+}$ ions water adjusted to $\mathrm{pH}$ using $2 \mathrm{M} \mathrm{NaOH}$ solution. The gel beads were stirred over night at room temperature.

\section{Testing the activity of the prepared gel beads as chelating materials}

The adsorption experiments were performed by addition of $1 \mathrm{~g}$ of beads to $10 \mathrm{~mL}$ of $\mathrm{Ca}^{2+}, \mathrm{Mg}^{2+}$ and $\mathrm{Fe}^{2+} / \mathrm{Fe}^{3+}$ at different concentrations ranging from 100 to $600 \mathrm{mg} / \mathrm{L}$ for $2 \mathrm{~h}$ with gentle stirring at room temperature. The beads in this size have high density and they decant. So, they can be easily separated from the solution via separating the supernatant (clean solution) from the beads. Concentrations of $\mathrm{Ca}^{2+}$ and $\mathrm{Mg}^{2+} \mathrm{Fe}^{2+} / \mathrm{Fe}^{3+}$ in the filtrate were measured using atomic absorption spectroscopy (PerkinElmer 3110, USA). Each experiment was carried out three times, and the average value is presented. The results of the experiments are presented in Fig. 2 and Tables 1, 2 and 3.

\section{Results and discussion}

Production of gel beads was prepared using the encapsulator to obtain beads with diameter $\sim 2 \mathrm{~mm}$, measured using the micrometer. The polyanionic biopolymers can

Table 1 Optimization of concentration of cations ${ }^{\mathrm{a}}$

\begin{tabular}{|c|c|c|c|c|c|c|}
\hline \multirow[t]{2}{*}{ Carrier } & \multicolumn{2}{|l|}{ Calcium } & \multicolumn{2}{|l|}{ Iron } & \multicolumn{2}{|l|}{ Magnesium } \\
\hline & Opt. \% removed & $\mathrm{mg}$ removed & Opt. \% removed & $\mathrm{mg}$ removed & Opt. \% removed & $\mathrm{mg}$ removed \\
\hline Chitosan & 75 & 2.47 & 80 & 3.20 & 82 & 3.36 \\
\hline Alginate & 69 & 3.45 & 85 & 3.40 & 63 & 1.89 \\
\hline Carrageenan & 78 & 2.49 & 92 & 2.85 & 72 & 2.30 \\
\hline
\end{tabular}

One gram of chitosan, carrageenan and modified alginate beads was soaked in $10 \mathrm{~mL}$ containing $1-5 \mathrm{mg}$ of cations (100-500 mg/L) cations for $2 \mathrm{~h}$

Table 2 Optimization of amount of beads to remove cations

\begin{tabular}{|c|c|c|c|c|c|c|c|c|c|}
\hline \multirow[t]{2}{*}{ Carrier } & \multirow{2}{*}{$\begin{array}{l}\text { Opt. beads } \\
\text { weight gm }\end{array}$} & \multicolumn{2}{|l|}{ Calcium } & \multirow{2}{*}{$\begin{array}{l}\text { Opt. beads } \\
\text { weight gm }\end{array}$} & \multicolumn{2}{|l|}{ Iron } & \multirow{2}{*}{$\begin{array}{l}\text { Opt. beads } \\
\text { weight gm }\end{array}$} & \multicolumn{2}{|c|}{ Magnesium } \\
\hline & & $\begin{array}{l}\text { Opt. \% } \\
\text { removed }\end{array}$ & $\begin{array}{l}\mathrm{mg} / \mathrm{L} \\
\text { removed }\end{array}$ & & $\begin{array}{l}\text { Opt. \% } \\
\text { removed }\end{array}$ & $\begin{array}{l}\mathrm{mg} / \mathrm{L} \\
\text { removed }\end{array}$ & & $\begin{array}{l}\text { Opt. \% } \\
\text { removed }\end{array}$ & $\begin{array}{l}\mathrm{mg} / \mathrm{L} \\
\text { removed }\end{array}$ \\
\hline Chitosan & 2.0 & 100 & 5.00 & 2.0 & 100 & 5.00 & 2.0 & 85 & 4.25 \\
\hline Alginate & 2.5 & 73 & 3.65 & 2.0 & 100 & 5.00 & 2.0 & 90 & 4.50 \\
\hline Carrageenan & 2.5 & 85 & 4.25 & 1.5 & 100 & 5.00 & 2.0 & 98 & 4.90 \\
\hline
\end{tabular}

Amount of 0.25-3.0 $\mathrm{g}$ of chitosan, carrageenan and modified alginate beads was soaked in $10 \mathrm{~mL}$ containing $5 \mathrm{mg}$ of cations $(500 \mathrm{mg} / \mathrm{L})$ for $2 \mathrm{~h}$

Table $3 \%$ Chelation efficiency for metal cations using $2 \mathrm{~g}$ of gel beads

\begin{tabular}{llll}
\hline $\begin{array}{l}\text { Carrier }(2 \mathrm{~g}) \text { in } 10 \mathrm{~mL} \text { containing } 500 \mu \mathrm{g} \text { of cations } \\
\text { for } 2 \mathrm{~h}\end{array}$ & $\begin{array}{l}\text { Calcium, \% chelation } \\
\text { efficiency }\end{array}$ & $\begin{array}{l}\text { Iron, \% chelation } \\
\text { efficiency }\end{array}$ & $\begin{array}{l}\text { Magnesium, } \% \text { chelation } \\
\text { efficiency }\end{array}$ \\
\hline Chitosan & 100 & 100 & 85 \\
Alginate & 60 & 100 & 90 \\
Carrageenan & 70 & 100 & 98 \\
\hline
\end{tabular}

Two grams of gel beads was soaked in $10 \mathrm{~mL}$ containing $500 \mu \mathrm{g}$ of cations for $2 \mathrm{~h}$ 
provide binding sites to remove metal ions from aqueous solutions via coordination interaction (chemical interaction) between the metal cations and the functional groups existing in the biopolymer such as free carboxyl groups for the treated alginate; free amino and hydroxyl groups for chitosan and free sulfonic; and hydroxyl groups for the carrageenan. Firstly, the prepared and modified gel beads were screened on $500 \mathrm{mg} / \mathrm{L}$ of $\mathrm{Ca}^{2+}$ solutions to test the activity of gel beads in removing $\mathrm{Ca}^{2+}$ cations, and it was showed that carrageenan and chitosan chelated $\mathrm{Ca}^{2+}$ ions without modification on their surface beads. But, the alginate needed some modification to remove calcium ions

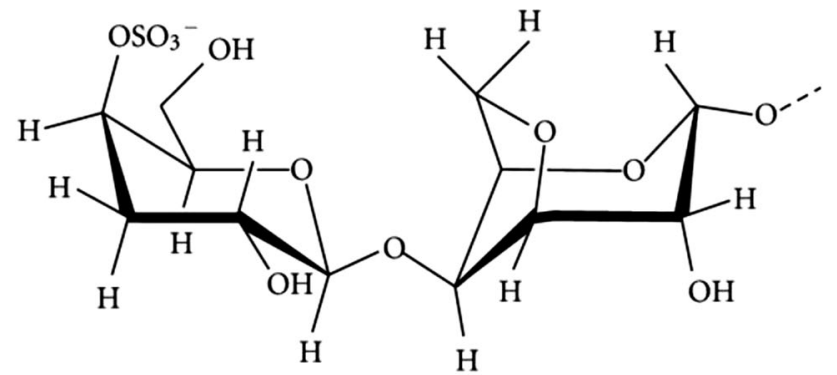

(a)

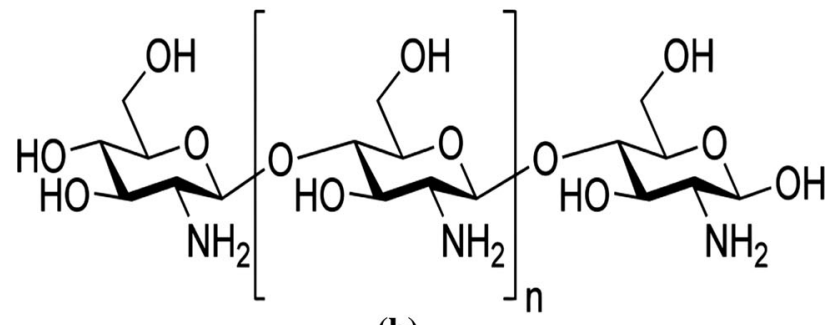

(b)

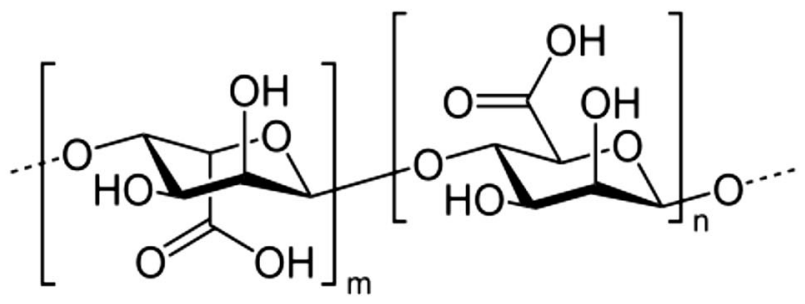

(c)

Fig. 3 a Carrageenan structure. b Chitosan structure. c Alginate structure

Fig. 4 Functionalization of alginate by PEI and bromoacetic acid from the solution (Fig. 2). That could be due to the fact that alginate beads were solidified in calcium chloride solution; thus, further modification of calcium was a must.

The presence of $\mathrm{HSO}_{3}{ }^{-}$and $\mathrm{HO}^{-}$groups on carrageenan beads (Fig. 3a) can chelate and remove $\mathrm{Ca}^{2+}$ cations from the solution. The activity of carrageenan beads was sharply decreased from $2.35 \mathrm{mg} / \mathrm{g}$ beads $(235 \mathrm{mg} / \mathrm{L})$ after the grafting process using PEI and bromoacetic acid to $0.8 \mathrm{mg} / \mathrm{g}$ beads $(80 \mathrm{mg} / \mathrm{L})$. That could be due to the functionalization process that led to blocking of some of $\mathrm{HSO}_{3}{ }^{-}$groups on the carrageenan that were used during the chelation process with calcium cations.

Chitosan is composed of randomly distributed $\beta$-linked D-glucosamine and N-acetyl-D-glucosamine and contains adjacent $\mathrm{NH}_{2}$ and $\mathrm{HO}^{-}$groups (Fig. 3b) that can chelate and remove $\mathrm{Ca}^{2+}$ cations from the solution.

Interestingly, this study showed that the concentration of $\mathrm{Ca}^{2+}$ ions increased in the solution after its treatment with alginate beads (Fig. 3c). That could be due to the fact that alginate beads were previously cross-linked by calcium chloride solution, and when the beads were soaked in calcium solution, the beads were already saturated with calcium ions and some of the physically bound calcium ions were liberated. The overall calcium concentration had increased by $1.5 \mathrm{mg} / \mathrm{g}$ beads $(150 \mathrm{mg} / \mathrm{L})$ as shown in Fig. 2 .

To solve this problem, two functionalization reactions have been applied on the alginate beads (previously treated and cross-linked with calcium chloride) to be able to chelate the divalent cations. Firstly, alginate beads were treated with PEI to prepare polymeric beads containing $\mathrm{NH}_{2}$ and $\mathrm{OH}$ groups (Fig. 4). Secondly, the latter was modified with bromoacetic acid to prepare polymeric beads containing free $-\mathrm{COOH}$ and $-\mathrm{OH}$ groups (Fig. 4). The IR spectra for the alginate and modified alginate beads were measured, and the results revealed the presence of new $\mathrm{OH}$ and $\mathrm{C}=\mathrm{O}$ groups, at vmax 3449 and $1743 \mathrm{~cm}^{-1}$, respectively, which are due to the new carboxylic group (Fig. 5). The three steps of alginate beads formation and treatment were studied to remove calcium ions from solutions as shown in Fig. 2, and the results were as follows:

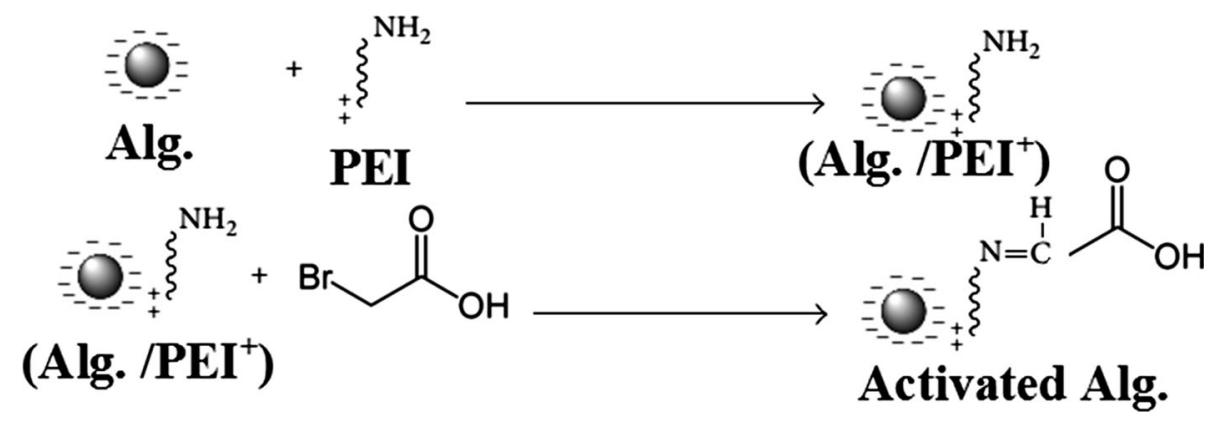




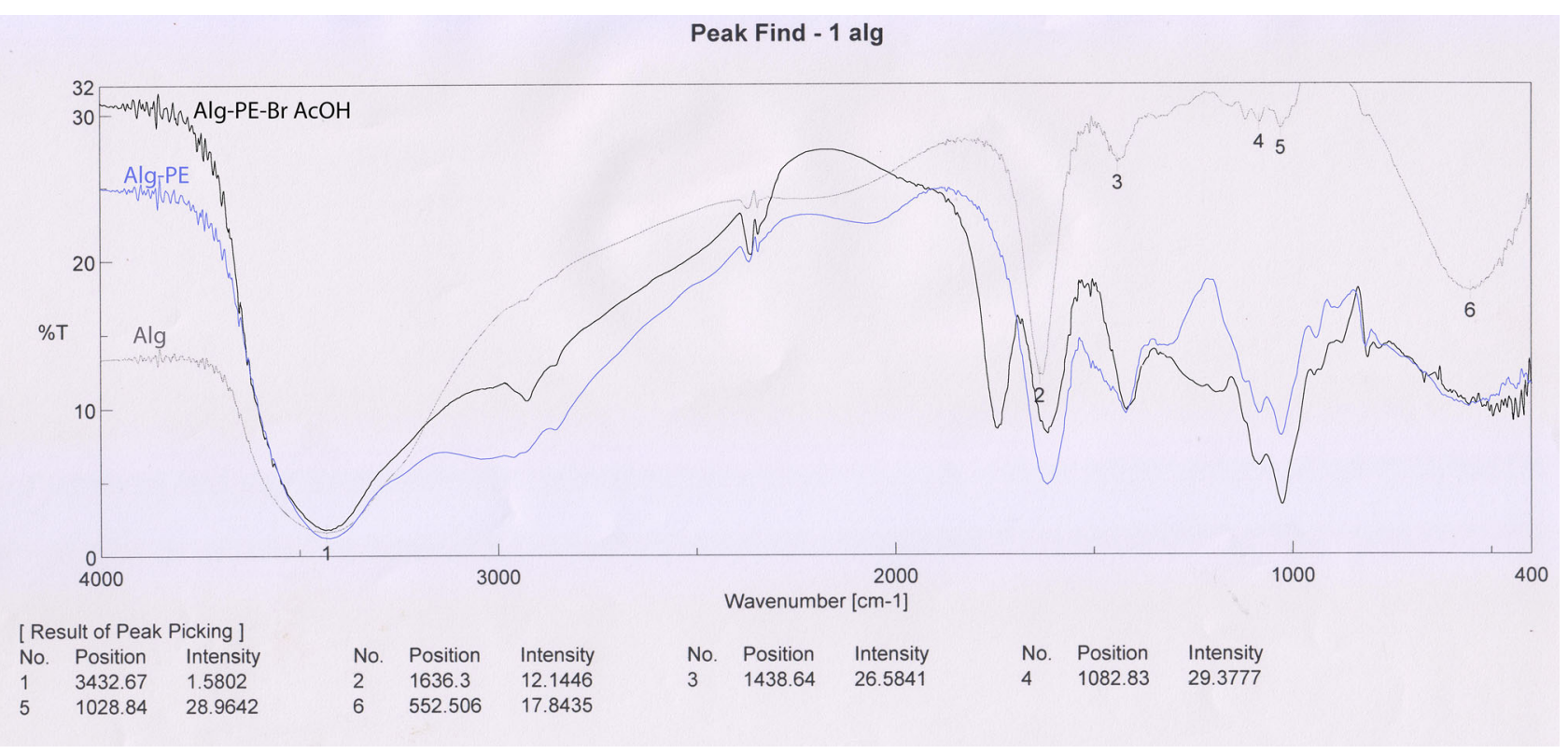

Fig. 5 IR spectra for Alg, Alg-PE and Alg-PE-Br-AcOH beads

1. The cross-linked alginate beads with calcium chloride as a cross-linker did not remove any calcium ions; on contrary, more calcium ions from the beads were added to the calcium solution to increase its concentration by $1.5 \mathrm{mg} / \mathrm{g}$ beads $(150 \mathrm{mg} / \mathrm{L})$.

2. The treated calcium chloride beads with PEI removed $200 \mathrm{mg} / \mathrm{L}$ calcium ions from the solution, and this is due to chelation of calcium ions using the free amino groups.

3. The treated calcium chloride beads with PEI followed by bromoacetic acid removed significant amount of calcium ions, $220 \mathrm{mg} / \mathrm{L}$, and this could be due to chelation of calcium ions using the free carboxylic groups.

After screening the activity of the prepared biopolymers toward $\mathrm{Ca}^{2+}$ solutions, the conditions of the experiments were optimized in order to reach the optimum conditions to remove the different cations, iron, magnesium and calcium.

\section{Optimum conditions of chitosan beads to remove cations}

Chitosan gel beads $(1 \mathrm{~g})$ were soaked in $10 \mathrm{~mL}$ of calcium, magnesium and iron solutions at different concentrations ranging from 100 to $500 \mathrm{mg} / \mathrm{L}$ for $2 \mathrm{~h}$.

\section{Optimum amount of chitosan beads for chelation of cations}

For determination of the required amount of chitosan beads for optimum chelation of $\mathrm{Ca}^{2+}, \mathrm{Mg}^{2+}$ and $\mathrm{Fe}^{2+} / \mathrm{Fe}^{3+}$, different weights of beads ranging from 0.25 to $3 \mathrm{~g}$ were soaked in $10 \mathrm{ml}$ of $500 \mathrm{mg} / \mathrm{L}$ of cations.

\section{Optimum conditions of alginate beads to remove cations}

One gram of modified alginate gel beads treated with bromoacetic acid was soaked in calcium, magnesium and iron solutions at different concentrations ranging from 100 to $500 \mathrm{mg} / \mathrm{L}$ for $2 \mathrm{~h}$.

\section{Optimum amount of alginate beads for chelation of cations}

For the determination of the required amount of alginate beads for optimum chelation of $\mathrm{Ca}^{2+}, \mathrm{Mg}^{2+}$ and $\mathrm{Fe}^{2+} / \mathrm{Fe}^{3+}$, different weights of alginate beads ranging from 0.25 to $3 \mathrm{~g}$ were soaked in $10 \mathrm{ml}$ of $500 \mathrm{mg} / \mathrm{L}$ of metal concentration. The results presented in Tables 1, 2 and 3 revealed that the optimum amount of modified alginate beads was $2.5 \mathrm{~g}$ to remove $73 \%$ of $\mathrm{Ca}^{2+}$ and $2 \mathrm{~g}$ of modified alginate beads to remove $90 \%$ of $\mathrm{Mg}^{2+}$ and $100 \%$ of $\mathrm{Fe}^{2+} / \mathrm{Fe}^{3+}$.

\section{Optimum conditions of carrageenan beads to remove cations}

One gram of carrageenan gel beads was soaked in calcium, magnesium and iron solutions at different concentrations ranging from 100 to $500 \mathrm{mg} / \mathrm{L}$ for $2 \mathrm{~h}$.

\section{Optimum amount of carrageenan beads for chelation of cations}

For the determination of the required amount of beads for complete removal of iron and magnesium cations, different 
weights of beads ranging from 0.25 to $3 \mathrm{~g}$ were soaked in $10 \mathrm{ml}$ of $500 \mathrm{mg} / \mathrm{L}$ of metal concentration.

\section{Comparative summary of results}

In Tables 1 and 2 are summarized the data obtained from optimization of gel beads and cation concentrations (Figures not shown) in a comparative way as follows:

The results in Table 1 show that the maximum amount of chelated calcium and iron was 3.45 and $3.40 \mathrm{mg}$, using $1 \mathrm{~g}$ of treated alginate, respectively, whereas $3.36 \mathrm{mg}$ of magnesium was removed using $1 \mathrm{~g}$ of chitosan beads. These results were further optimized by using $0.25-3.0 \mathrm{~g}$ of chitosan, carrageenan and modified alginate to chelate a fixed concentration of cations at $500 \mathrm{mg} / \mathrm{L}$, and the results are given in Table 2.

The results in Table 2 show an outstanding improvement in the chelation power of the biopolymeric beads reaching almost their maximum capacity to chelate 85$100 \%$ of the cations. In terms of efficiency and from an economic point of view, the amount of chelated cations per $2 \mathrm{~g}$ bead or $\%$ efficiency were calculated as shown in Table 3 using the following equation.

\section{$\%$ Chelation efficiency $=$ \\ [[Chelated cations in $\mathrm{mg} / 2 \mathrm{~g}$ beads] \\ /Initial amount of cations in $\mathrm{mg}] * 100$}

According to Table 3 and from an economic point of view, it is recommended to use chitosan for chelation of calcium and iron as it showed $100 \%$ chelation efficiency of both cations, whereas carrageenan is highly recommended for the chelation of iron and magnesium, as it showed $100 \%$ and $98 \%$ chelation efficiency, respectively. It is also worth to note that chitosan is the second most abundant biopolymer in nature after cellulose. Furthermore, chitosan and carrageenan did not need any further modification, which are more economic and friendlier to the environment compared to alginate, which required further treatment.

\section{Conclusion}

Three biopolymeric beads based on chitosan, carrageenan and alginate were prepared for treatment of hard water from calcium, magnesium and iron. It was found that alginate could not chelate calcium ions from the solutions because of the pre-preparation of alginate beads using calcium chloride, which leaked back into the solution. Accordingly, it was further cross-linked with PEI and bromoacetic acid. The three formulations were optimized to chelate the three cations, and the results were outstanding as they could remove $60-100 \%$ of the cations. Results showed that chitosan and carrageenan showed better chelation capabilities and they also did not require any further modification, which are more economic and friendlier to the environment compared to alginate. Thus, for future work, it will be interesting to concentrate on the use of carrageenan and chitosan. Furthermore, we plan to use the prepared beads on the semi-pilot scale to prove its efficiency on the scale up process and its reusability.

Acknowledgements This work was supported by the National Research Centre-Egypt under the 10th project Grant (Project No. 10080101).

\section{References}

Ali KA, Haroun AA, Abd El-Moez SI (2013) Synthesis and antimicrobial activity of gelatin-thiazolidine derivative based nanohybrids. In: CIMDD conference at Algeria: May 6th to 9th, 2013. UniversitéM'HamedBougaraBoumerdes

Chaturvedi S, Dave PN (2012) Removal of iron for safe drinking water. Desalination 313:1-11

Deans JR, Dixon BG (1992) Uptake of $\mathrm{Pb}^{2+}$ and $\mathrm{Cu}^{2+}$ by novel biopolymers. Water Res 26:469-472

Elnashar MM (2010) Immobilized molecules using biomaterials and nanobiotechnology. J Biomater Nanobiotechnol 1:61-76

Elnashar MM (2011) The art of immobilization using biopolymers, biomaterials and nanobiotechnology, biotechnology of biopolymers, Chap 1, pp 1-32. ISBN:978-953-307-179-4

Elnashar MM, Hassan ME (2014) Novel epoxy activated hydrogels for solving lactose intolerance. Biomed Res Int 2014:817985

Elnashar MM, Danial EN, Awad EA (2009) Novel carrier of grafted alginate for covalent immobilization of inulinase. Ind Eng Chem Res 48:9781-9785

El-Sayed MH, Hani HA, Sorour MH (2014) Polymeric ion exchangers for the recovery of ions from brine and seawater. Chem Eng Process Tech 2:1020

Jang LK, Lopez SL, Eastman SL, Prygogle P (1991) Recovery of copper and cobalt by biopolymer gels. Biotechnol Bioeng 37:266-273

Muraviev D, Noguerol J, Valiente M (1996) Separation and concentration of calcium and magnesium from sea water by carboxylic resins with temperature induced selectivity. React Funct Polym 28:111-126

Nah CJ, Hwang K (2007) Adsorption of heavy metals using magnetically modified alginic acid. Hydrometallurgy 86:140-146

Nazarudin MF, Shamsuri AA, Shamsudin MN (2011) Preparation and physicochemical evaluation of biodegradable magnetic $\kappa$-carrageenan beads and application for chromium ions pre-concentration. J Chil Chem Soc 56:891-894

Ohya H, Suzuki T, Nakao S (2001) Integrated system for complete usage of components in seawater. Desalination 134:29-36

Seki H, Suzuki A (1995) Adsorption of heavymetal ions on insolubilized humic acid. J Colloid Interface Sci 171:490-494

Zhao L, Shi L, Zhang Z, Chen J, Shi D, Yang J, Tang Z (2011) Preparation and application of chitosan nanoparticles and nanofibers. Braz J Chem Eng 28:353-362 